Article

\title{
Study of Bond Strength of Steel Bars in Basalt Fibre Reinforced High Performance Concrete
}

\section{Piotr Smarzewski $\mathbb{D}$}

Department of Structural Engineering, Faculty of Civil Engineering and Architecture, Lublin University of Technology, 20-618 Lublin, Poland; p.smarzewski@pollub.pl; Tel.: +48-698-695-284

Received: 22 April 2020; Accepted: 28 May 2020; Published: 29 May 2020

\begin{abstract}
The paper presents the study on bond behaviour of steel bars. It reports the research conducted on local bond strength of short length specimens in high performance concrete (HPC) and basalt fibre reinforced high performance concrete (BFRHPC). In this study, the basalt fibre volume content, concrete cover, bar diameter and rib geometry are the main parameters. Further important factors are the directions of the casting and loading. Determining the effect of aforementioned main parameters on the bond strength in test series is required, in order to design reinforced HPC structures. The study of local bond strength in HPC and BFRHPC with five different basalt fibre fractions included tests of seventy-two short length specimens, using two concrete cover and two diameters of steel bars with different rib face angles. For different ranges of BFRHPC strength, relationships for bond strength with respect to the splitting tensile strength were obtained. The bond strength increased with the splitting tensile strength and compressive strength of BFRHPC specimens with the $12 \mathrm{~mm}$ and $16 \mathrm{~mm}$ bar respectively. The bond strength of BFRHPC was lower for the bar with the greater distances between the lugs on the bar.
\end{abstract}

Keywords: bond strength; high performance concrete; reinforcing steel bar; basalt fibre

\section{Introduction}

High performance concrete (HPC) has compressive strength above $80 \mathrm{MPa}$ and low permeability. A serious disadvantage of this composite is brittleness, which increases with strength. Numerous researchers have revealed that steel and polypropylene fibres [1-6] or combinations of these fibres [7-10] can reduce the brittleness of HPC and significantly improve its tensile strength and fracture toughness, as well as its ductility.

Basalt fibres produced from molten basalt rock have very good strength properties, as well as high resistance to fire and alkaline environment, and at the same time are relatively cheap. These characteristics determine their use in concrete [11,12]. However, the cost in addition to the chemical and mechanical properties of basalt fibres vary, depending of the type and quality of the raw material and the production process of these fibres [13]. Nevertheless, the above-mentioned characteristics and an environmentally friendly manufacturing process [14] might determine their application in HPC structures, instead of the most commonly used steel and polypropylene fibres.

The research into basalt fibre reinforced concrete (BFRC) has largely been focused on fundamental mechanical properties, such as compressive, splitting tensile and flexural strength, as well as fracture toughness [11,12,14-18]. Fibre reinforced high performance concrete (FRHPC) is widely regarded as an excellent composite for use in sustainable construction [19-21]. However, optimum fibre dosages vary significantly in different types of concrete, such as geopolymeric concrete [5], normal strength concrete [14,17], high performance concrete [16,19-21] or ultra-high performance concrete [22-25]. Although the basalt fibre reinforced high performance concrete (BFRHPC) has good tensile strength, the rather poor ductility of this composite [19-21] means that concrete structures with basalt fibres 
should contain steel or other reinforcing bars to achieve the required performance and reliability. For this reason, a good interfacial bond of BFRHPC to steel bars is an important determinant of the interaction of these two materials in the structure.

Designing reinforced HPC structures with basalt fibres requires knowledge of the bond behaviour of steel reinforcement. Due to the high compressive strength, HPC elements have small cross-sections, and for this reason, the concrete cover and the failure mode are the most important parameters. When using fibres, knowledge about their impact on the bond behaviour and the possibility of replacing transverse reinforcement is very important [26]. In construction practice, the bar diameter, rib geometry, pouring direction of concrete and load direction are also relevant.

The bond strength between concrete and reinforcing bars in short lengths depends, among other factors, on the bar diameter, concrete strength and concrete cover. The theory of partly cracked thick cylinder proposed by Tepfers is the most comprehensive approach for determining the local bond, although it does not take into account the effect of deformation properties and the geometry of ribs in reinforcing bars [27]. This theory assumes that an uncracked concrete ring confines the cracked concrete and the reinforcing bar, and is resistant to bursting stresses radiating outwards from the bar at an angle of $45^{\circ}$ to the bar axis. Soretz and Holzenbein [28] reported that the bonding action is different when the rib face angle is less than $30^{\circ}$, and they presented the dependence of the deformation pattern on the behaviour of local bond stress-slip as a function of the relative rib area. Darwin and Graham revealed that a bar with a smaller rib face angle results in lower bond strength [29]. Hwang et al. [30] determined the impact of silica fume on the splice strength of deformed bars embedded in high strength concrete (HSC) and noted that the bond strength of a beam at 10\% cement replacement by silica fume was $15 \%$ lower than the beam bond strength with no silica fume addition. Tests carried out on beams with a long embedded length showed that the bond stresses differ significantly along the length [31]. Esfahani and Rangan [32] studied the bond strength in HPC concrete and estimated the maximum bond stress based on the results of short length specimens in which the distribution of the bond stresses at failure was almost uniform. Local bond equations were proposed in this investigation that can be used to determine the maximum bond stress at the ends of the splices. Holschemacher et al. [33] showed that the high brittleness of the composite does not adversely affect the bond behaviour of steel bars anchored in ultra-high strength concrete. The binding stiffness increased, due to the high elastic modulus and compressive strength of concrete. Eligehausen et al. [34] examined different failure modes of anchoring bars (pull-out, pry-out and splitting) in normal strength concrete. It was found that the various failure modes were influenced by different parameters, such as confinement, relative rib area, fibre addition, concrete cover and casting direction. Alkaysi and El-Tawil [35] performed pull-out tests to characterize the bond strength of a non-proprietary ultra-high performance concrete mixture, and revealed that the bond strength decreases with increased embedment length and increases with higher volume content of steel fibres.

\section{Research Significance}

Designing reinforced concrete structures is relied on the bond relationship between the concrete and the steel bar. However, investigations of the interfacial bond behaviour between BFRHPC and steel bars have not yet been published, and remain a pressing need. The experimental program described in this article fills this gap and aimed to quantify the bond strength between HPC and steel reinforcement for several important design parameters. To assess the effect of different parameters on the bond, the maximum bond stress was required, which was estimated from the test results of short length specimens and an almost uniform distribution of the bond stresses at failure. A total of 72 bar pull-out tests were performed with parameters including average bar coatings $(43 \mathrm{~mm}, 93 \mathrm{~mm})$, nominal bar diameter $(12 \mathrm{~mm}, 16 \mathrm{~mm})$ and fibre volume content $(0 \%, 1 \%, 1.25 \%, 1.5 \%, 1.75 \%$ and $2 \%)$. The present study is part of an investigation on the bond strength in high and ultra-high performance concrete with the application of hybrid fibres. Several relationships for the bond strength with respect to the splitting tensile strength and fibre volume fractions of BFRHPC were suggested. In addition, the equations 
obtained in this study for determining the local bond strength can be used as the maximum bond stress at the ends of the splices.

\section{Materials and Methods}

HPC was made with general use Portland cement CEM I 52.5R (C) (CEMEX, Chełm, Poland), non-densified silica fume (SF) (Ironworks Łaziska, Łaziska Górne, Poland), tap water (W) and well-graded coarse and fine aggregates (CA, FA). The physical properties and chemical compositions of cementitious materials are summarized in Table 1.

Table 1. Chemical compositions and physical properties of used cement and silica fume.

\begin{tabular}{ccc}
\hline Composition (\%) & Cement & Silica Fume \\
\hline $\mathrm{SiO}_{2}$ & 19.99 & 85.0 \\
$\mathrm{Al}_{2} \mathrm{O}_{3}$ & 4.19 & - \\
$\mathrm{Fe}_{2} \mathrm{O}_{3}$ & 3.76 & - \\
$\mathrm{CaO}$ & 64.82 & 1.0 \\
$\mathrm{MgO}$ & 1.14 & - \\
$\mathrm{SO}_{3}$ & 3.25 & 2.0 \\
$\mathrm{~K}_{2} \mathrm{O}$ & 0.46 & - \\
$\mathrm{Na}_{2} \mathrm{O}$ & 0.24 & 3.0 \\
$\mathrm{Cl}$ & 0.07 & 0.3 \\
$\mathrm{Si}$ & - & 0.4 \\
Loss on ignition & 3.01 & 4.0 \\
Insoluble matter & 0.18 & - \\
\hline Specific surface area (cm $\left.{ }^{2} / \mathrm{g}\right)$ & 4839 & 150,000 \\
Water demand $(\%)$ & 30 & - \\
Start of setting (min) & 160 & - \\
End of setting (min) & 210 & - \\
Compressive strength at 2 days (MPa) & 40.3 & - \\
Tensile strength at 2 days (MPa) & 6.5 & - \\
\hline
\end{tabular}

Superplasticizer CX ISOFLEX 793 (CEMEX Admixtures GmbH, Salzkotten, Germany) (Sp) based on polycarboxylate ethers was used in high dosage. The $12 \mathrm{~mm}$ lengths of chopped basalt fibers (Holtex, Rzgów, Poland) (BF) were used. The basalt fibre bundles are flat, approximately $1 \mathrm{~mm}$ wide and made of $13 \mu \mathrm{m}$ diameter filaments. Other characteristics of the fibre were as follows: density $2.7 \mathrm{~g} / \mathrm{cm}^{3}$, modulus of elasticity $70 \mathrm{GPa}$, tensile strength $1700 \mathrm{MPa}$ and elongation at break $2.5 \%$. The fibres used in this study are shown in Figure 1a. The ribbed bars, on which the bond strength was determined, were B500SP with diameters of $12 \mathrm{~mm}$ and $16 \mathrm{~mm}$. Axial tensile tests were carried out on three specimens for each diameter of reinforcing bars (Figure 1b).

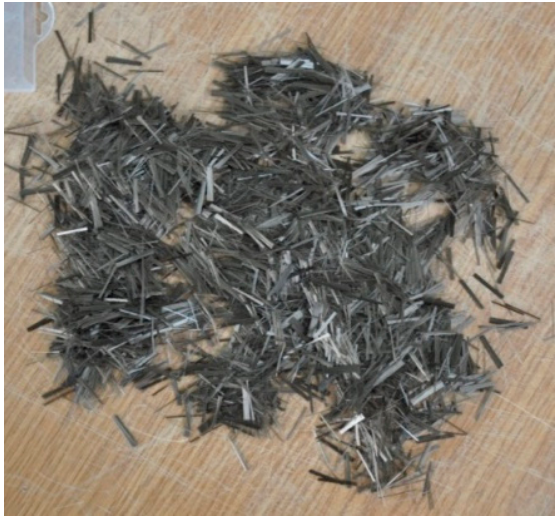

(a)

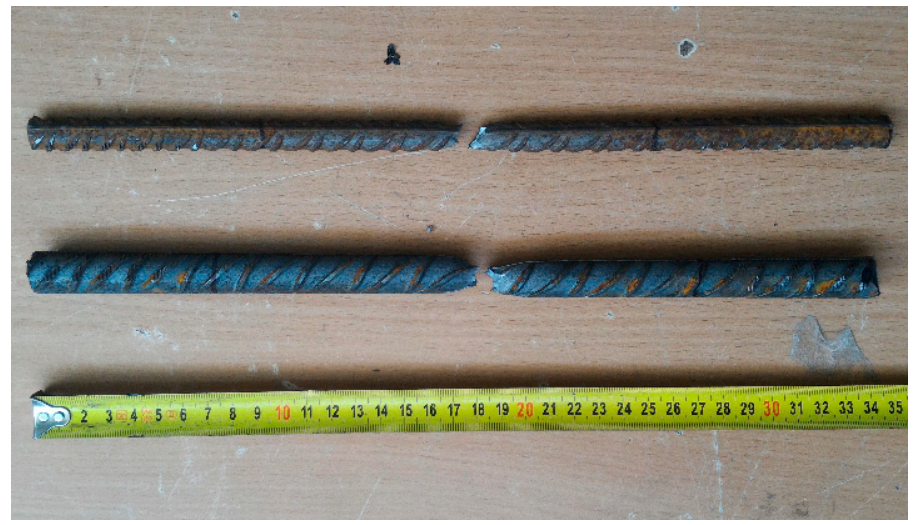

(b)

Figure 1. (a) Fibres used in experimental work; (b) reinforcing bars after tensile test. 
The measured yield strength, tensile strength, elastic modulus, ultimate tensile strain and minimum relative rib area of $12 \mathrm{~mm}$ and $16 \mathrm{~mm}$ were $605 \mathrm{MPa}, 691 \mathrm{MPa}, 203 \mathrm{GPa}, 33 \%, 0.040 \mathrm{~mm}^{2}$ and $622 \mathrm{MPa}, 716 \mathrm{MPa}, 211 \mathrm{GPa}, 27 \%, 0.056 \mathrm{~mm}^{2}$ respectively. In order to measure the rib geometries, the reinforcing bars were longitudinally sliced. The rib face angle in the $12 \mathrm{~mm}$ and $16 \mathrm{~mm}$ bars was between $37^{\circ}$ and $73^{\circ}$, as well as $44^{\circ}$ and $73^{\circ}$, correspondingly. The measured distances between the ribs for the above-mentioned bars were from 3 to $6 \mathrm{~mm}$ and from 6 to $12 \mathrm{~mm}$, respectively.

HPC specimens used in this investigation were cast with a 0.28 water-binder ratio. The silica fume had a specific surface of $15 \mathrm{~m}^{2} / \mathrm{g}$. The basalt coarse aggregate (CA) had a maximum size of $5 \mathrm{~mm}$, fineness modulus of 5.92 and compressive strength of $196 \mathrm{MPa}$. The fine quartz sand aggregate (FA) had a maximum particle size of $2 \mathrm{~mm}$ and fineness modulus of 1.84 . The quantities used in the reference mixture were as follows: cement $-670.5 \mathrm{~kg} / \mathrm{m}^{3}$, silica fume $-74.5 \mathrm{~kg} / \mathrm{m}^{3}$, coarse aggregate $-990 \mathrm{~kg} / \mathrm{m}^{3}$, fine aggregate $-500 \mathrm{~kg} / \mathrm{m}^{3}$, water $-210 \mathrm{~L} / \mathrm{m}^{3}$, and superplasticizer $-20 \mathrm{~L} / \mathrm{m}^{3}$. The reference mixture HPC-B0 did not contain any basalt fibres. The following five contained fibres with an aspect ratio of $l / d=923$ and percentage ranging from $1 \%$ to $2 \%$ were made with a reduced quartz sand amount equal to the weight of the added fibres. A summary of the all mixture types in this work is shown in Table 2.

Table 2. Test mixture proportions.

\begin{tabular}{|c|c|c|c|c|c|c|c|c|}
\hline \multirow{2}{*}{ Designation } & \multirow{2}{*}{$\underset{\left(\mathrm{kg} / \mathrm{m}^{3}\right)}{\mathrm{C}}$} & \multirow{2}{*}{$\begin{array}{c}\mathrm{SF} \\
\left(\mathrm{kg} / \mathrm{m}^{3}\right)\end{array}$} & \multirow{2}{*}{$\underset{\left(\mathrm{kg} / \mathrm{m}^{3}\right)}{\mathrm{CA}}$} & \multirow{2}{*}{$\underset{\left(\mathrm{kg} / \mathrm{m}^{3}\right)}{\text { FA }}$} & \multirow{2}{*}{$\begin{array}{c}W \\
\left(L / m^{3}\right)\end{array}$} & \multirow{2}{*}{$\underset{\left(L / m^{3}\right)}{S p}$} & \multicolumn{2}{|c|}{ BF } \\
\hline & & & & & & & $\left(\mathrm{kg} / \mathrm{m}^{3}\right)$ & $(\%)$ \\
\hline HPC-B0 & 670.5 & 74.5 & 990 & 500 & 210 & 20 & 0 & 0 \\
\hline HPC-B1 & 670.5 & 74.5 & 990 & 473 & 210 & 20 & 27 & 1 \\
\hline HPC-B1.25 & 670.5 & 74.5 & 990 & 466.25 & 210 & 20 & 33.75 & 1.25 \\
\hline HPC-B1.5 & 670.5 & 74.5 & 990 & 459.5 & 210 & 20 & 40.5 & 1.5 \\
\hline HPC-B1.75 & 670.5 & 74.5 & 990 & 452.75 & 210 & 20 & 47.25 & 1.75 \\
\hline HPC-B2 & 670.5 & 74.5 & 990 & 446 & 210 & 20 & 54 & 2 \\
\hline
\end{tabular}

Two different types of deformed bars with nominal diameters of $12 \mathrm{~mm}$ and $16 \mathrm{~mm}$ were used in pull-out tested specimens. Seventy-two specimens in six series were produced and examined. All the specimens were cast parallel to the steel bar fixed vertically in the mould according to the pre-adopted position of the bar. Thirty-six specimens were made for each bar using six different basalt fibre contents of $0 \%, 1 \%, 1.25 \%, 1.5 \%, 1.75 \%$ and $2 \%$. There were three specimens for each combination of $c_{y} / \phi_{b}$ and fibre content. The ratios of the side cover to the bottom cover of the concrete $\left(c_{x} / c_{y}\right)$ were 1 and 2.1. The details of the pull-out test specimens and test set-up are shown in Table 3 and Figure 2.

Table 3. Details of test specimens.

\begin{tabular}{cccccc}
\hline $\begin{array}{c}\text { Bar Diameter } \\
\phi_{\boldsymbol{b}}(\mathbf{m m})\end{array}$ & $\begin{array}{c}\text { Bottom Concrete } \\
\text { Cover, } \boldsymbol{c}_{\boldsymbol{y}}(\mathbf{m m})\end{array}$ & $\begin{array}{c}\text { Side Concrete } \\
\text { Cover, } \boldsymbol{c}_{\boldsymbol{x}}(\mathbf{m m})\end{array}$ & $\begin{array}{c}\text { Embedded } \\
\text { Length, } \boldsymbol{l}_{\boldsymbol{e}}(\mathbf{m m})\end{array}$ & $\boldsymbol{c}_{\boldsymbol{y}} / \boldsymbol{\phi}_{\boldsymbol{b}}$ & $\begin{array}{c}\text { Number of } \\
\text { Specimens }\end{array}$ \\
\hline 12 & 94 & 94 & 60 & 7.83 & 18 \\
12 & 44 & 94 & 60 & 3.67 & 18 \\
16 & 92 & 92 & 80 & 5.75 & 18 \\
16 & 42 & 92 & 80 & 2.63 & 18 \\
\hline
\end{tabular}



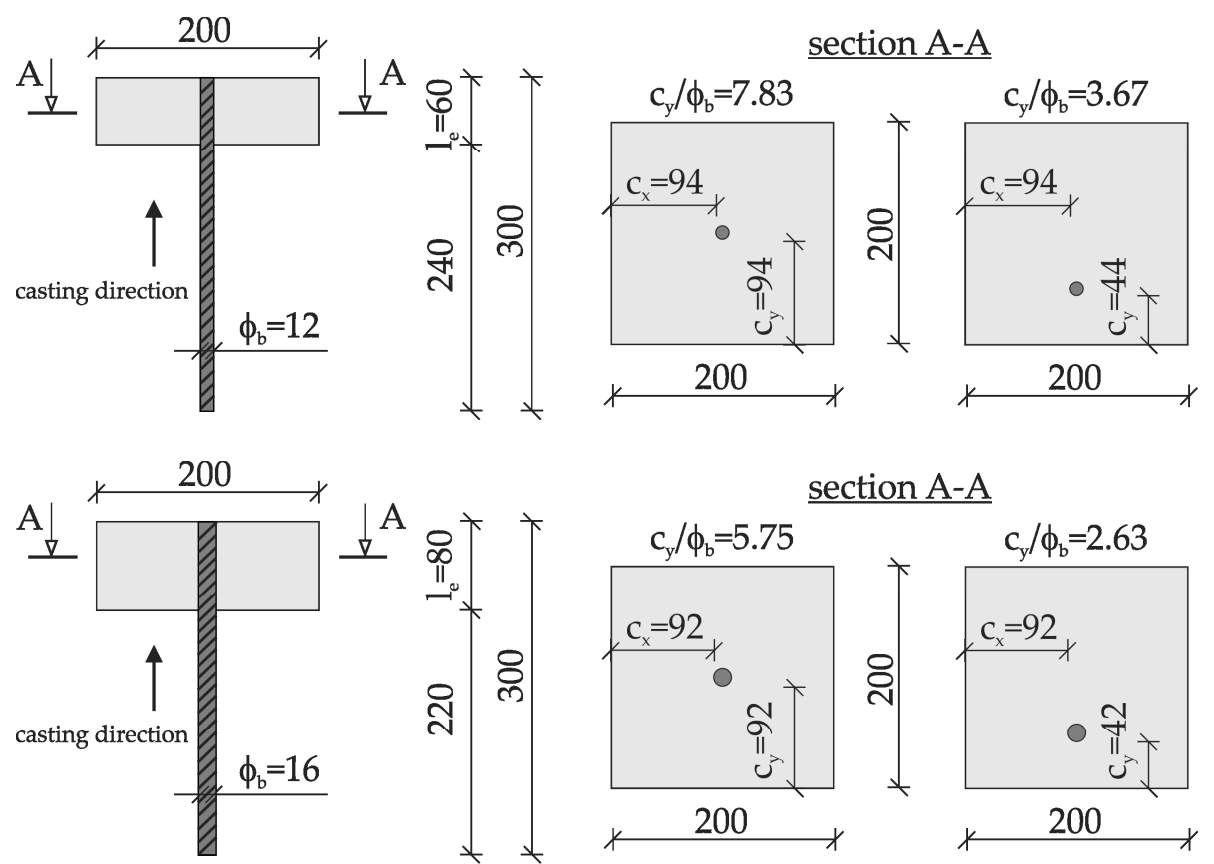

(a)

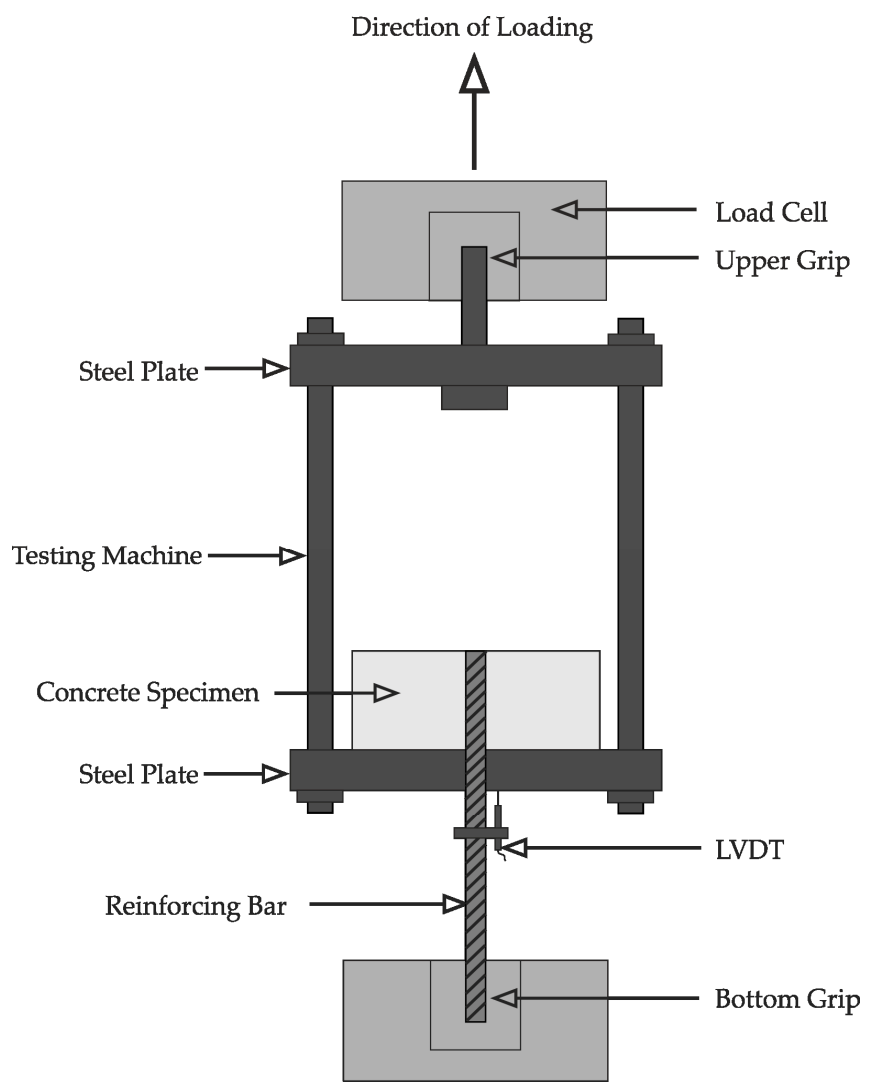

(b)

Figure 2. (a) Test specimen details (dimensions in $\mathrm{mm}$ ), (b) test set-up.

To investigate the bond behaviour of steel bars embedded in HPC and BFRHPC, a pull-out test was carried out. A pull-out load was applied using the MTS 319.25 servo-hydraulic testing machine 
(MTS, Eden Prairie, MN, USA) with a maximum flexural load capacity of $250 \mathrm{kN}$ under displacement control, with a rate of $1 \mathrm{~mm} / \mathrm{min}$ during testing. The LVDT was used to measure bond slip between the reinforcing bar and the HPC/BFRHPC at the loaded end. In all specimens, longitudinal cracking of the concrete cover occurred over the anchorage length of the reinforcing bars before failure. All the specimens failed due to splitting of concrete.

For each casting, seventy-two $100 \mathrm{~mm} \times 100 \mathrm{~mm} \times 100 \mathrm{~mm}$ HPC cubes were made to determine the compressive and splitting tensile strength. These strength tests were carried out using an Advantest 9 load-controlled universal press (CONTROLS, Milan, Italy) of $3 \mathrm{MN}$ capacity. The average of six measurements was recorded as the compressive and splitting tensile strength of each HPC. Eighteen $100 \mathrm{~mm} \times 100 \mathrm{~mm} \times 500 \mathrm{~mm}$ beam specimens were made to set the flexural strength. The bending tests were subjected to three-point loading using the MTS 319.25 press (MTS, Eden Prairie, MN, USA). The beam specimens were supported on two rolls spaced at a distance of $300 \mathrm{~mm}$ and then were loaded at the midspan. The flexural tests used deflection as the control signal at a rate of $0.05 \mathrm{~mm} / \mathrm{min}$. The average of the flexural strength of three beam specimens was reported for each HPC.

\section{Results and Discussion}

\subsection{Hardened State Properties}

Table 4 gives the results of the compressive strength, splitting tensile strength and flexural strength for all HPC at 28 days, with standard deviations (SD) and coefficients of variation. The ratio of plain HPC strength to basalt fibre reinforced HPC strength are also presented.

Table 4. Mechanical properties of high performance concretes (HPCs).

\begin{tabular}{|c|c|c|c|c|c|c|}
\hline Property & HPC-B0 & HPC-B1 & HPC-B1.25 & HPC-B1.5 & HPC-B1.75 & HPC-2 \\
\hline Compressive strength (MPa) & 135.5 & 112.1 & 112.3 & 116.4 & 111.1 & 105.3 \\
\hline $\mathrm{SD}(\mathrm{MPa})$ & 1.85 & 1.31 & 1.31 & 1.17 & 1.38 & 1.21 \\
\hline CV $(\%)$ & 1.36 & 1.17 & 1.17 & 1.00 & 1.24 & 1.15 \\
\hline Ratio & 1.00 & 0.83 & 0.83 & 0.85 & 0.82 & 0.78 \\
\hline Splitting tensile strength (MPa) & 6.4 & 8.0 & 9.0 & 9.6 & 7.9 & 7.7 \\
\hline $\mathrm{SD}(\mathrm{MPa})$ & 0.15 & 0.21 & 0.29 & 0.19 & 0.11 & 0.23 \\
\hline CV (\%) & 2.34 & 2.62 & 3.22 & 1.98 & 1.39 & 2.99 \\
\hline Ratio & 1.00 & 1.25 & 1.41 & 1.50 & 1.23 & 1.20 \\
\hline Flexural strength (MPa) & 6.0 & 10.1 & 10.8 & 12.4 & 11.5 & 12.2 \\
\hline $\mathrm{SD}(\mathrm{MPa})$ & 0.15 & 0.23 & 0.39 & 0.29 & 0.21 & 0.33 \\
\hline CV (\%) & 2.50 & 2.28 & 3.61 & 2.34 & 1.83 & 2.70 \\
\hline Ratio & 1.00 & 1.68 & 1.80 & 2.07 & 1.92 & 2.03 \\
\hline
\end{tabular}

The results indicate that the basalt fibre volume content influenced the compressive strength in fibre content range considered from $0 \%$ to $2 \%$. The compressive strength of HPC was reduced by $15-22 \%$, with an increase in the fibre volume fraction with comparison with that of HPC without fibres. This can be clarified by higher porosity in the fibre reinforced concrete due to the air infiltration during the mixing procedure of the fibres and concrete [36]. Additionally, it was observed that basalt fibres can absorb water from the cement paste, and reduce the HPC fluidity and compressive strength [19]. Although the addition of basalt fibres resulted in a decrease in compressive strength, they noticeably enhanced the toughness of the HPC under compression. The literature also suggests that the primary benefit of basalt fibres in concrete under compression is the change from a brittle failure mode to a more ductile mode $[11,14,16,17]$.

It can be noticed that the tensile splitting and flexural strength of BFRHPC is always greater than these of HPC for the reason that basalt fibres act as crack-arrestors. Such an action may be assigned to the basalt fibres role in gradually filling micro-cracks, which leads to increased bonding in high performance concrete microstructure, and, consequently, to higher splitting tensile strength and flexural strength. 
The addition of basalt fibre to normal strength concrete can significantly increase its splitting tensile and flexural strength. Jiang et al. [11] revealed that basalt fibres with $12 \mathrm{~mm}$ length and between $0.30 \%$ and $0.5 \%$ by volume content increased the flexural strength and splitting tensile strength of normal strength concrete by $9.58 \%$ and $24.34 \%$, respectively. Kabay [37] obtained $10.3 \%$ increase in flexural strength when $2 \mathrm{~kg} / \mathrm{m}^{3}$ and $4 \mathrm{~kg} / \mathrm{m}^{3}$ basalt fibres were added to normal strength concrete. Çelik and Bingöl [38] stated that the addition of basalt fibre at $0.20 \%$ volume content increase flexural strength of self-compacting concrete $11.58 \%$. On the other hand, the highest splitting tensile strength was observed at $0.30 \%$ basalt fibre content, which increased by $12.78 \%$ according to the plain specimen.

The maximum values of split tensile and flexural strength were reached for HPC with $1.5 \%$ basalt fibre fraction. It was found that its tensile strengths compared to reference mixture increased by $50 \%$ and $106.67 \%$, respectively. The decreases in average split tensile and flexural strength of HPC with $1.75 \%$ and $2 \%$ basalt fibre contents may be related to the variable distribution of fibres and the tendency to group them in these mixtures. Çelik and Bingöl [38] also observed a reduction in the flexural strength of self-compacting concrete with an increase in the addition of basalt fibres from $0.2 \%$ to $0.25 \%$. They found that may be due to the fact that the low flexibility of basalt fibres caused the formation of larger voids in the concrete and deteriorated the distribution of fibres.

Concerning the tensile strength results, the flexural strength exhibited more variability and much higher results than splitting strength. Considering the CV values given in Table 4, it can be observed that the addition of basalt fibres did not increase the error indicators.

Çelik and Bingöl [38] studied normal strength concrete with basalt fibres with a volume fraction of $0.30 \%$ at 28 days. Based on micrographs analyses, it was noticed that there are voids between basalt fibres and cement paste, which reduce fibre-matrix bond and, as a consequence, rather brittle post-cracking behaviour occurs in basalt fibre reinforced composites. Branston et al. [14] also found that the density of cement on the basalt fibre surface decreases considerably after nine months. However, high performance concrete is characterised by a dense interfacial transition zone (ITZ), and behaves differently to normal strength concrete. Wu et al. [39] performed microstructure analyses of the steel fibre in ultra-high performance concrete matrix, calculated changes in porosity with the distance from the edge of the fibre and found that the porosity decreased as the distance from the edge of the fibre increased. The porosity around the fibre at $50 \mu \mathrm{m}$ was $47 \%$ lower than the porosity at $10 \mu \mathrm{m}$ from the fibre edge. On this basis, it can be assumed that the porosity of high performance concrete with basalt fibres will also grow with increasing fibre content, and smaller distances between the fibres, which consequently results in a decrease in HPC strength.

\subsection{Bond Strength Versus Fibre Content Relationship}

The average values of bond properties are summarized in Table 5. The bond strength was calculated as the achieved pull-out force divided by the initial surface area of the embedded bar by means of the relation $\boldsymbol{T}_{\mathrm{b}}=F_{\max } / \pi \phi_{b} l_{e}$ where $F_{\max }$ is the maximum force in the bar at bond failure in the specimen. It is important to note that splitting failure mode did represent a bond failure in all the HPC specimens.

Table 5 shows the increase in nominal and normalized bond strength with increasing basalt fibre volume content up to $1.5 \%$. This is caused by that since the deformed steel bar provides bonding through interlocking between the rebar lugs and the surrounding concrete, the bond strength increases with increasing strength of the surrounding high performance concrete [40]. In addition, the average displacement at peak load increased when the basalt fibre content increased, similar to the bond strength. The average normalized bond strength from all tested series was obtained as 1.2. The fibre content had a significant impact on this value. It can be seen that the normalized bond strength was twice as high in concrete with $2 \%$ fibre content, as compared to plain HPC.

Figure 3 compares the bond strength versus the fibre content relationships using two different $c_{y} / \phi_{b}$ relations for two bar diameters $\phi_{b}$, namely $12 \mathrm{~mm}$ and $16 \mathrm{~mm}$. The error indicator denotes the standard deviation. 


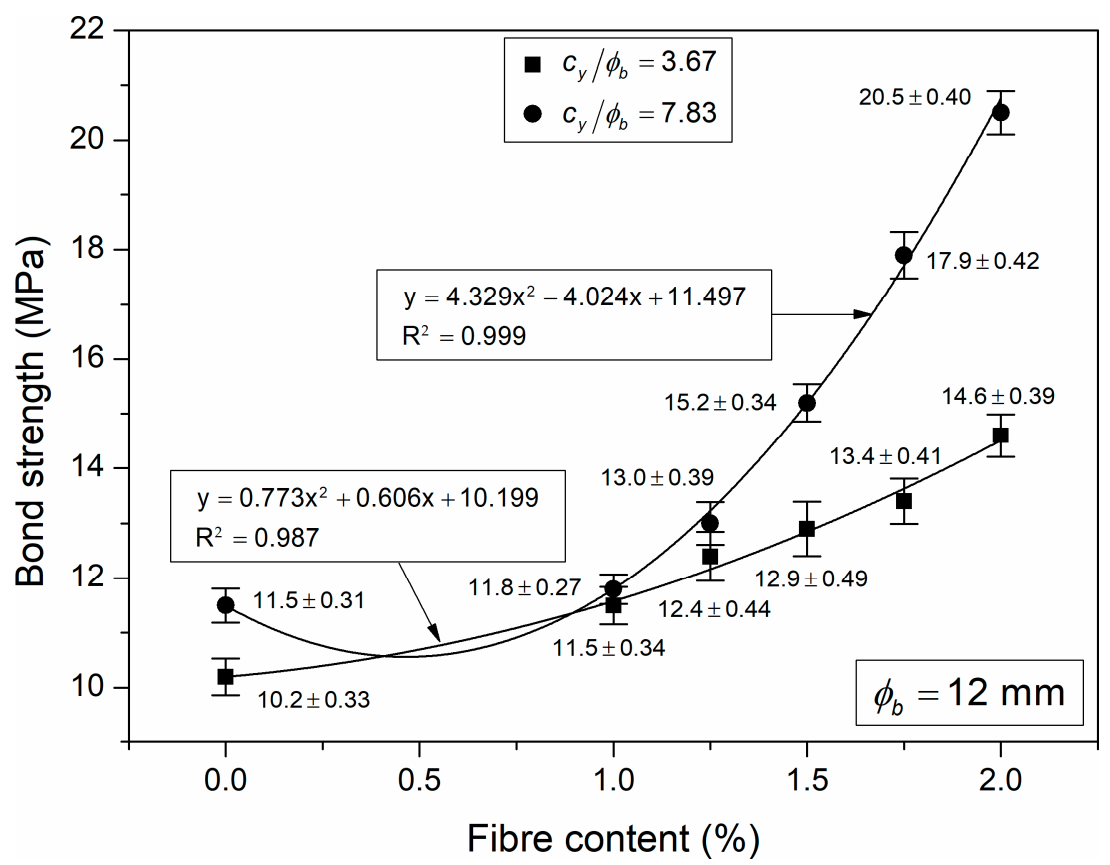

(a)

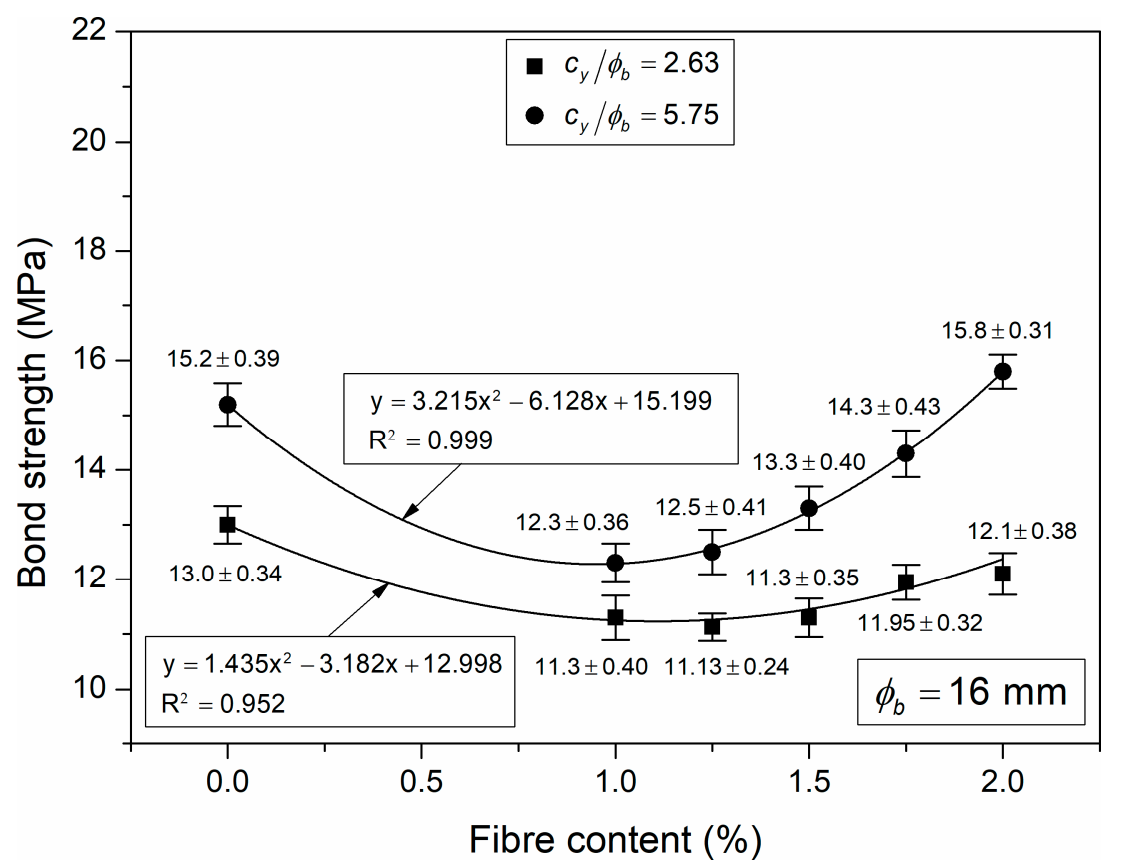

(b)

Figure 3. Variation in bond strength with fibre content for different bar diameters $\phi_{b}$ and relations $c_{y} / \phi_{b}$ (a) $12 \mathrm{~mm}$, (b) $16 \mathrm{~mm}$.

The comparison of the results in Figure 3a shows that, for different values of $c_{y} / \phi_{b}$, the bond strengths of the $12 \mathrm{~mm}$ bar increase with a growing basalt fibre content, and with an increasing concrete cover. The bond strengths of HPC-B0 were 11.5 MPa with the central position of the bar in the specimen and $10.5 \mathrm{MPa}$ with the bar positioned halfway between the centre and the edge of the specimen and of BFRHPC provided an improvement at each volume fraction. The bond strength improvement of the $12 \mathrm{~mm}$ bar located axially in the specimens and pulled-out of BFRHPC ranged from $2.6 \%$ to $78.3 \%$ at the volume fractions from $1.0 \%$ to $2.0 \%$, as well as form $12.7 \%$ to $43.1 \%$ for the eccentric pulled-out bar from BFRHPC at the same fractions. In contrast, the bond strength of the $16 \mathrm{~mm}$ bar falls when the 
fibre content is $1-1.25 \%$ (Figure $3 b$ ). The decreases ranged between $6.9 \%$ and $13.1 \%$ for an eccentric bar and reduced with higher fibre content. A similar downward trend in the range of 5.9-19.1\% was maintained for the centrally located bar. Only for the $2 \%$ fibre volume fraction a slight $3.9 \%$ increase in the bond strength was noted. In the case of concrete without fibres, the bond strength was greater for the $16 \mathrm{~mm}$ bar in the range of 24.3-27.4\%. This can be explained by the larger rib face angle between $44^{\circ}$ to $73^{\circ}$ of the $16 \mathrm{~mm}$ bar than in the $12 \mathrm{~mm}$ bar with a rib face angle from $37^{\circ}$ to $73^{\circ}$. The lower values of bond strengths of BFRHPC for the $16 \mathrm{~mm}$ bar can be clarified by the larger distances between the ribs from 6 to $12 \mathrm{~mm}$, compared to the $12 \mathrm{~mm}$ bar, in which these distances are between 3 to $6 \mathrm{~mm}$. At larger distances between the lugs on the bar, the short basalt fibres could be oriented parallel to the bar between the ribs causing faster bond failure occurring, as a result of shearing off and crushing the concrete. This effect was observed for the smallest concrete cover. This indicates that the bond strength of the steel bar depends on the HPC strength. The BFRHPC compressive strength used in this study was $15-22 \%$ lower, compared to the concrete without fibres, and the splitting tensile strength was $20-50 \%$ higher.

Table 5. Summary of pull-out test results.

\begin{tabular}{|c|c|c|c|c|c|c|c|c|c|c|}
\hline Designation & $\begin{array}{c}V_{f} \\
(\%)\end{array}$ & $\begin{array}{c}f_{c} \\
(\mathbf{M P a})\end{array}$ & $\begin{array}{c}\phi_{b} \\
(\mathrm{~mm})\end{array}$ & $\begin{array}{c}l_{e} \\
(\mathrm{~mm})\end{array}$ & $\begin{array}{c}c_{y} \\
(\mathrm{~mm})\end{array}$ & $\begin{array}{c}c_{x} \\
(\mathrm{~mm})\end{array}$ & $\begin{array}{l}F_{\max } \\
(\mathbf{k N})\end{array}$ & $\begin{array}{c}\tau_{b} \\
(\mathrm{MPa})\end{array}$ & $\begin{array}{c}\delta_{m} \\
(\mathrm{~mm})\end{array}$ & $\begin{array}{c}\tau_{b}{ }^{*} \\
(\mathrm{MPa})\end{array}$ \\
\hline \multirow[t]{4}{*}{ HPC-B0 } & 0 & 135.5 & 12 & 60 & 94 & 94 & 26.01 & 11.5 & 1.66 & 0.99 \\
\hline & & & & & 44 & 94 & 23.07 & 10.2 & 2.16 & 0.88 \\
\hline & & & 16 & 80 & 92 & 92 & 61.12 & 15.2 & 3.77 & 1.31 \\
\hline & & & & & 42 & 92 & 52.28 & 13.0 & 3.58 & 1.12 \\
\hline \multirow[t]{4}{*}{ HPC-B1 } & 1.0 & 112.1 & 12 & 60 & 94 & 94 & 26.69 & 11.8 & 3.52 & 1.11 \\
\hline & & & & & 44 & 94 & 26.01 & 11.5 & 4.47 & 1.09 \\
\hline & & & 16 & 80 & 92 & 92 & 49.46 & 12.3 & 4.53 & 1.16 \\
\hline & & & & & 42 & 92 & 45.44 & 11.3 & 5.67 & 1.07 \\
\hline \multirow[t]{4}{*}{ HPC-B1.25 } & 1.25 & 112.3 & 12 & 60 & 94 & 94 & 29.41 & 13.0 & 5.90 & 1.23 \\
\hline & & & & & 44 & 94 & 28.05 & 12.4 & 6.56 & 1.17 \\
\hline & & & 16 & 80 & 92 & 92 & 50.27 & 12.5 & 5.62 & 1.18 \\
\hline & & & & & 42 & 92 & 44.64 & 11.1 & 5.25 & 1.05 \\
\hline \multirow[t]{4}{*}{ HPC-B1.5 } & 1.5 & 116.4 & 12 & 60 & 94 & 94 & 34.38 & 15.2 & 5.95 & 1.41 \\
\hline & & & & & 44 & 94 & 29.18 & 12.9 & 8.33 & 1.20 \\
\hline & & & 16 & 80 & 92 & 92 & 53.48 & 13.3 & 6.77 & 1.23 \\
\hline & & & & & 42 & 92 & 45.44 & 11.3 & 6.31 & 1.05 \\
\hline \multirow[t]{4}{*}{ HPC-B1.75 } & 1.75 & 111.1 & 12 & 60 & 94 & 94 & 40.49 & 17.9 & 5.99 & 1.70 \\
\hline & & & & & 44 & 94 & 30.31 & 13.4 & 7.32 & 1.27 \\
\hline & & & 16 & 80 & 92 & 92 & 57.50 & 14.3 & 5.69 & 1.36 \\
\hline & & & & & 42 & 92 & 48.25 & 12.0 & 6.72 & 1.14 \\
\hline \multirow[t]{4}{*}{ HPC-B2 } & 2.0 & 105.3 & 12 & 60 & 94 & 94 & 46.37 & 20.5 & 6.23 & 2.00 \\
\hline & & & & & 44 & 94 & 33.02 & 14.6 & 4.24 & 1.42 \\
\hline & & & 16 & 80 & 92 & 92 & 63.54 & 15.8 & 7.89 & 1.54 \\
\hline & & & & & 42 & 92 & 48.66 & 12.1 & 6.73 & 1.18 \\
\hline
\end{tabular}

$V_{f}=$ volume content of fibre, $f_{c}=$ mean value of compressive strength, $\phi_{b}=$ bar diameter, $l_{e}=$ embedded length, $c_{y}, c_{x}=$ bottom and side concrete cover, $F_{\max }=$ maximum pull-out load, $\tau_{b}=$ bond strength, $\delta_{m}=$ mean value of displacement at peak load, $\tau_{b}{ }^{*}=$ normalized bond strength, $\tau_{b}^{*}=\tau_{b} / \sqrt{f_{c}}$.

\subsection{Bond Strength Versus Splitting Tensile Strength Relationship}

Figure 4 presents the bond strength versus splitting tensile strength relations for test series, using two different types of bars within a limited range of basalt fibre percentages.

The error indicators denote the standard deviations both the bond strength $(0.24-0.49 \mathrm{MPa})$ and splitting tensile strength $(0.15-0.29 \mathrm{MPa})$. The given relationships were proposed for basalt fibre content between $0 \%$ and $1.5 \%$, due to problems with proper fibre distribution at $1.75 \%$ and $2 \%$ fibre volume contents, which resulted in a significant reduction of $18.8 \%$ in splitting tensile strength of BFRHPC. As can be seen in Figure 4, the values of BFRHPC bond strength for test with the $16 \mathrm{~mm}$ bar 
test are higher in the range of $4.2-32.2 \%$ than the bond strength in the $12 \mathrm{~mm}$ bar for the $0-1 \%$ fibre volume fraction. On the other hand, with fibre contents of $1.25-1.5 \%$, it can be seen that the $12 \mathrm{~mm}$ bars were characterized by higher bond strengths in the range of $4-14.3 \%$. It can be reported that the bond strength for the $12 \mathrm{~mm}$ bar increases when the BFRHPC splitting tensile strength growths. In contrast, the bond strength for the specimens with the $16 \mathrm{~mm}$ bar is higher when the concrete compressive strength growing (see Table 4). This is probably due to different geometry of the ribs in the $16 \mathrm{~mm}$ bar, as well as a different orientation of the fibres around the larger diameter bar, which may cause local sliding surfaces resulting in less values of the bond strength. Therefore, the extent of the concrete crushing in front of the ribs decreased as the compressive concrete strength increased.

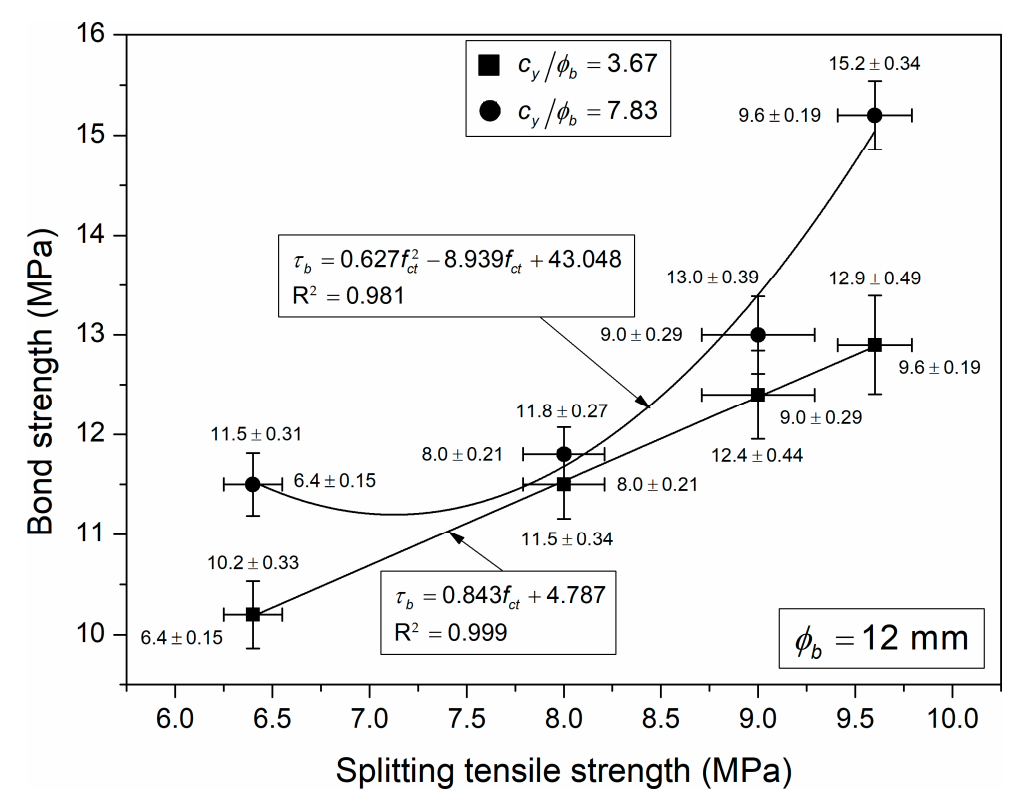

(a)

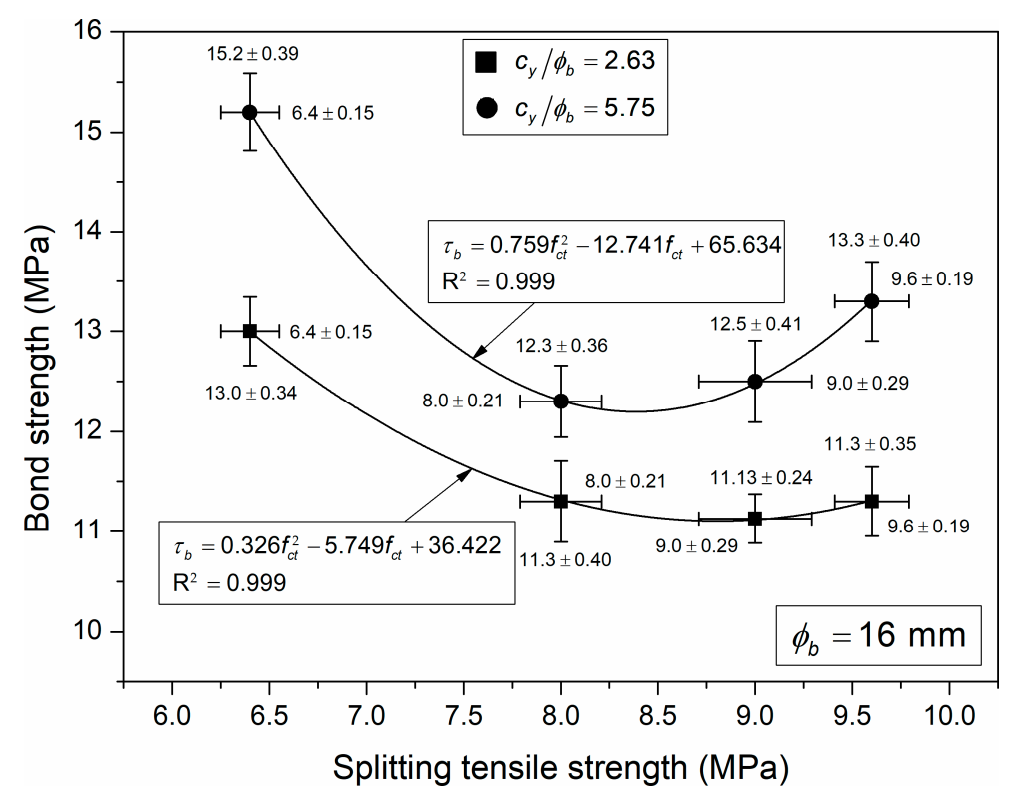

(b)

Figure 4. Variation in bond strength with splitting tensile strength for different bar diameters $\phi_{b}$ and relations $c_{y} / \phi_{b}(\mathbf{a}) 12 \mathrm{~mm},(\mathbf{b}) 16 \mathrm{~mm}$. 


\subsection{Bond Strength Versus Ratio of Concrete Cover to Bar Diameter Relationship}

The values for the bond strength of BFRHPC are shown in Figure 5 as a function of $c_{y} / \phi_{b}$ ratio. Linear regression leads to the relationships of the concrete cover to bar diameter ratio versus bond strength given in Table 6. The test data for two different bars are grouped together in the analysis.

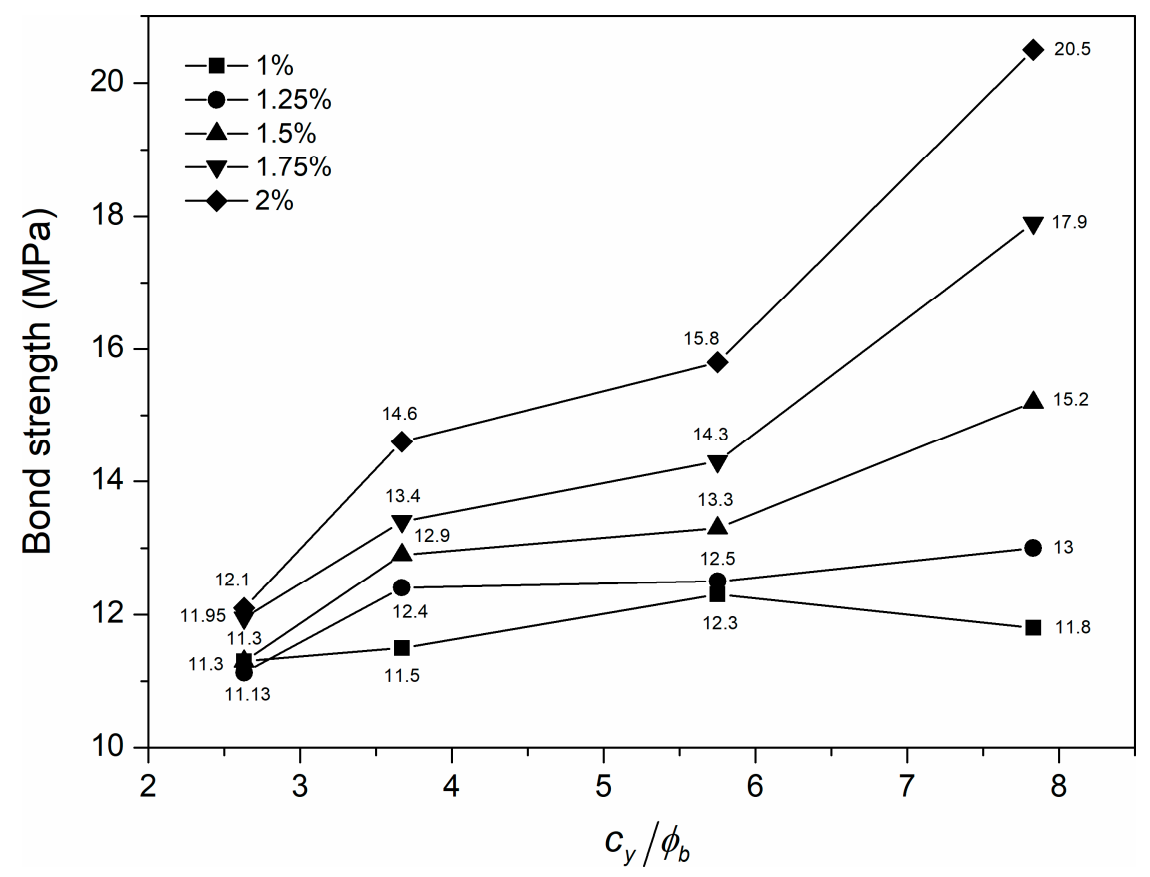

Figure 5. Variation in bond strength with $c_{y} / \phi_{b}$ ratio for different basalt fibre volume content.

Table 6. Ratio of concrete cover to bar diameter-bond strength relationship of basalt fibre reinforced high performance concrete (BFRHPC).

\begin{tabular}{cccc}
\hline Designation & Equation & Reduced Chi-Square & Adj. R-Square \\
\hline HPC-B1 & $\tau_{b}=0.122 \frac{c_{y}}{\phi_{b}}+11.117$ & 0.165 & 0.420 \\
HPC-B1.25 & $\tau_{b}=0.299 \frac{c_{y}}{\phi_{b}}+10.773$ & 0.239 & 0.749 \\
HPC-B1.5 & $\tau_{b}=0.667 \frac{c_{y}}{\phi_{b}}+9.862$ & 0.310 & 0.920 \\
HPC-B1.75 & $\tau_{b}=1.063 \frac{c_{y}}{\phi_{b}}+9.102$ & 0.611 & 0.937 \\
HPC-B2 & $\tau_{b}=1.483 \frac{c_{y}}{\phi_{b}}+8.379$ & 1.060 & 0.971 \\
\hline
\end{tabular}

In general, the bond strength values for the BFRHPC specimens improved with increasing the basalt fibre content and $c_{y} / \phi_{b}$ ratio. For the $12 \mathrm{~mm}$ bars and $c_{y} / \phi_{b}$ ratios of 3.67 and 7.83 , the bond strength increased by $27 \%$ and $73.7 \%$, respectively, when the fibre volume content increased from $1 \%$ to $2 \%$. For the $16 \mathrm{~mm}$ bars and $c_{y} / \phi_{b}$ ratios of 2.63 and 5.75 , specimens containing $1 \%$ basalt fibres showed, in sequence, $6.6 \%$ and $22.1 \%$ lower bond strengths than specimens with $2 \%$ fibres. This seems to confirm the regularity that the bond strength depends on the quantity of fibres available to bridge any cracks formed under loading. Comparing the average bond strengths obtained for the $12 \mathrm{~mm}$ and $16 \mathrm{~mm}$ embedded bars, while maintaining a similar concrete cover and $2 \%$ fibre content, it was observed that the bond strength is up to $29.7 \%$ higher for a bar with a smaller diameter. Similar trends were noted for the remaining fibre volume fractions $1-1.75 \%$. It can be also concluded that suggested linear relations agree very well with the test results. The recorded bond strength values differed most at the lowest fibre content of $1 \%$ and $1.25 \%$, especially at greater concrete cover, which justifies further research. 


\section{Conclusions}

The objective of this study was to investigate the bond strength between basalt fibre reinforced high performance concrete and deformed steel bar. Simple pull-out tests were carried out at two different bar diameters, two concrete covers, two embedment lengths and six fibre volume contents. Seventy-two short length pull-out specimens were tested at 28 days. Based on this investigation, the following main conclusions were drawn:

- The compressive strength of HPC worsened with increasing basalt fibres volume fraction. The compressive strength ranged from $15 \%$ to $22 \%$ lower for the fractions from $1 \%$ to $2 \%$.

- The splitting tensile strength and flexural strength of BFRHPC significantly improved with the addition of basalt fibres at various volume contents. The splitting tensile and flexural strength showed a maximum at 1.5\% fibre content but slight decreases at $1.75 \%$ and $2 \%$ contents, compared to $1.5 \%$ still remaining $23 \%$ and $20 \%$ higher, as well as $92 \%$ and $103 \%$ higher than before the fibre's addition.

- Changes in basalt fibre content between $1 \%$ and $2 \%$ resulted in differences between $7 \%$ and $74 \%$ in the bond strength achieved. Similar differences in bond strength were observed after normalization, suggesting that the bond strength depends more on the quantity of fibres available to bridge any cracks forming under load, rather than the differences in compressive strength of BFRHPC.

- The bond strength for the same bar diameter and fibre volume content improved from 3\% to $40 \%$ with a two-fold concrete cover, suggesting that the bond strength is dependent on the fibre orientation in the concrete cover area.

- The relationships obtained for BFRHPC predict the bond strengths accurately.

Funding: This research was supported financially by the Polish Ministry of Science and Higher Education within statutory research project no. FN15/ILT/2020.

Acknowledgments: The financial support from the Polish Ministry of Science and Higher Education is greatly appreciated. The author would also like to thank the CEMEX Company for donating the cement and superplasticizer for this research.

Conflicts of Interest: The author declares no conflict of interest.

\section{References}

1. Sivakumar, A.; Santhanam, M. Mechanical properties of high strength concrete reinforced with metallic and non-metallic fibres. Cem. Concr. Compos. 2007, 29, 603-608. [CrossRef]

2. Smarzewski, P. Hybrid Fibres as Shear Reinforcement in High-Performance Concrete Beams with and without Openings. Appl. Sci. 2018, 8, 2070. [CrossRef]

3. Smarzewski, P. Analysis of Failure Mechanics in Hybrid Fibre-Reinforced High-Performance Concrete Deep Beams with and without Openings. Materials 2019, 12, 101. [CrossRef] [PubMed]

4. Smarzewski, P. Processes of Cracking and Crushing in Hybrid Fibre Reinforced High-Performance Concrete Slabs. Processes 2019, 7, 49. [CrossRef]

5. Afroughsabet, V.; Ozbakkaloglu, T. Mechanical and durability properties of high-strength concrete containing steel and polypropylene fibers. Constr. Build. Mater. 2015, 94, 73-82. [CrossRef]

6. Song, P.S.; Hwang, S. Mechanical properties of high-strength steel fiber-reinforced concrete. Constr. Build. Mater. 2004, 18, 669-673. [CrossRef]

7. Job, T.; Ramaswamy, A. Mechanical properties of steel fiber-reinforced concrete. J. Mater. Civ. Eng. 2007, 19, 385-392.

8. Ramezanianpour, A.A.; Ghahari, S.A.; Khazaei, A. Feasibility Study on Production and Sustainability of Poly Propylene Fiber Reinforced Concrete Ties Based on a Value Engineering Survey. In Proceedings of the Third International Conference on Sustainable Construction Materials and Technologies (SCMT3'13), Kyoto, Japan, 18-21 August 2013; pp. 1-8. 
9. Shah, A.A.; Ribakov, Y. Recent trends in steel fibered high-strength concrete. Mater. Des. 2011, 32, $4122-4151$. [CrossRef]

10. Feng, J.; Sun, W.; Zhai, H.; Wang, L.; Dong, H.; Wu, Q. Experimental study on hybrid effect evaluation of fiber reinforced concrete subjected to drop weight impacts. Materials 2018, 11, 2563. [CrossRef]

11. Jiang, C.; Fan, K.; Wu, F.; Chen, D. Experimental study on the mechanical properties and microstructure of chopped basalt fibre reinforced concrete. Mater. Des. 2014, 58, 187-193. [CrossRef]

12. High, C.; Seliem, H.M.; Adel El-Safty, A.; Rizkalla, S.H. Use of basalt fibers for concrete structures. Constr. Build. Mater. 2015, 96, 37-46. [CrossRef]

13. Fiore, V.; Scalici, T.; Di Bella, G.; Valenza, A. A review on basalt fibre and its composites. Compos. Part B Eng. 2015, 74, 74-94. [CrossRef]

14. Branston, J.; Das, S.; Kenno, S.Y.; Taylor, C. Mechanical behaviour of basalt fibre reinforced concrete. Constr. Build. Mater. 2016, 124, 878-886. [CrossRef]

15. Dias, D.P.; Thaumaturgo, C. Fracture toughness of geopolymeric concretes reinforced with basalt fibers. Cem. Concr. Compos. 2005, 27, 49-54. [CrossRef]

16. Ayub, T.; Shafiq, N.; Nuruddin, M.F. Mechanical properties of high-performance concrete reinforced with basalt fibers. Procedia Eng. 2014, 77, 131-139. [CrossRef]

17. Iyer, P.; Kenno, S.Y.; Das, S. Mechanical properties of fiber-reinforced concrete made with basalt filament fibers. J. Mater. Civ. Eng. 2015, 11, 04015015. [CrossRef]

18. Lipatov, Y.V.; Gutnikov, S.; Manylov, M.; Zhukovskaya, E.; Lazoryak, B. High alkali-resistant basalt fiber for reinforcing concrete. Mater. Des. 2015, 73, 60-66. [CrossRef]

19. Smarzewski, P. Flexural Toughness of High-Performance Concrete with Basalt and Polypropylene Short Fibres. Adv. Civ. Eng. 2018, 2018, 1-8. [CrossRef]

20. Smarzewski, P. Influence of basalt-polypropylene fibres on fracture properties of high performance concrete. Compos. Struct. 2019, 209, 23-33. [CrossRef]

21. Smarzewski, P. Flexural toughness evaluation of basalt fibre reinforced HPC beams with and without initial notch. Compos. Struct. 2020, 235, 111769. [CrossRef]

22. Yoo, D.-Y.; Shin, H.; Yang, J.-M.; Yoon, Y.-S. Material and bond properties of ultra high performance fiber reinforced concrete with micro steel fibers. Compos. Part B Eng. 2014, 58, 122-133. [CrossRef]

23. Smarzewski, P.; Barnat-Hunek, D. Fracture properties of plain and steel-polypropylene-fiber-reinforced high-performance concrete. Mater. Tehnol. 2015, 49, 563-571. [CrossRef]

24. Smarzewski, P. Effect of Curing Period on Properties of Steel and Polypropylene Fibre Reinforced Ultra-High Performance Concrete. IOP Conf. Ser. Mater. Sci. Eng. 2017, 245, 32059. [CrossRef]

25. Smarzewski, P. Study of Toughness and Macro/Micro-Crack Development of Fibre-Reinforced Ultra-High Performance Concrete After Exposure to Elevated Temperature. Materials 2019, 12, 1210. [CrossRef]

26. Fehling, E.; Lorenz, P.; Leutbeche, T. Experimental Investigations on Anchorage of Rebars in UHPC. In Proceedings of the International Symposium on Ultra High Performance Concrete, Kassel, Germany, 7-9 March 2012.

27. Tepfers, R. A Theory of Bond Applied to Overlapped Tensile Reinforcement Splices of Deformed Bars; Report 73-2; Chalmers University of Technology: Göteborg, Sweden, 1973.

28. Soretz, S.; Holzenbein, H. Influence of Rib Dimensions of Reinforcing Bars on Bond and Bendability. ACI J. 1979, 76, 111-126.

29. Darwin, D.; Graham, E.K. Effect of Deformation Height Spacing on Bond Strength of Reinforcing Bars. ACI Struct. J. 1993, 90, 646-657.

30. Hwang, S.J.; Lee, Y.Y.; Lee, C.S. Effect of Silica Fume Splice Strength of Deformed Bars of High-Performance Concrete. ACI Struct. J. 1994, 91, 294-302.

31. Tepfers, R. Bond stress along lapped reinforcing bars. Mag. Concr. Res. 1980, 32, 135-142. [CrossRef]

32. Local Bond Strength of Reinforcing Bars in Normal Strength and High-Strength Concrete (HSC). ACI Struct. J. 1998, 95, 96-106. [CrossRef]

33. Holschemacher, K.; Weiße, D.; Klotz, S. Bond of Reinforcement in Ultra High Strength Concrete. In Proceedings of the International Symposium on Ultra High Performance Concrete, Kassel, Germany, 13-15 September 2004.

34. Eligehausen, R.; Mallée, R.; Silva, J.F. Anchorage in Concrete Construction; Ernst\&Sohn: Berlin, Germany, 2006.

35. Alkaysi, M.; El-Tawil, S. Factors affecting bond development between Ultra High Performance Concrete (UHPC) and steel bar reinforcement. Constr. Build. Mater. 2017, 144, 412-422. [CrossRef] 
36. Wang, D.; Ju, Y.; Shen, H.; Xu, L. Mechanical properties of high performance concrete reinforced with basalt fiber and polypropylene fiber. Constr. Build. Mater. 2019, 197, 464-473. [CrossRef]

37. Kabay, N. Abrasion resistance and fracture energy of concretes with basalt fiber. Constr. Build. Mater. 2014, 50, 95-101. [CrossRef]

38. Çelik, Z.; Bingöl, A.F. Mechanical properties and postcracking behavior of self-compacting fiber reinforced concrete. Struct. Concr. 2019, 1-10. [CrossRef]

39. Wu, Z.; Khayat, K.H.; Shi, C. How do fiber shape and matrix composition affect fiber pullout behavior and flexural properties of UHPC? Cem. Concr. Compos. 2018, 90. [CrossRef]

40. Harajli, M.; Hamad, B.; Karam, K. Bond-slip response of reinforcing bars embedded in plain and fiber concrete. J. Mater. Civ. Eng. 2002, 14, 503-511. [CrossRef]

(C) 2020 by the author. Licensee MDPI, Basel, Switzerland. This article is an open access article distributed under the terms and conditions of the Creative Commons Attribution (CC BY) license (http://creativecommons.org/licenses/by/4.0/). 